\title{
Teor e fitoquímica de óleo essencial de manjericão em diferentes horários de colheita
}

\author{
Francisca Dayanne de Oliveira Alcantara ${ }^{1}$, Toshik Iarley da Silva ${ }^{2}$, Tamires Coelho Matias \\ Maciel $^{1}$, Cláudia Araújo Marco' ${ }^{1}$, Flávio Batista da Silva ${ }^{1}$
}

\author{
${ }^{1}$ Universidade Federal do Cariri, Juazeiro do Norte, Ceará, Brasil. E-mail:dayannealcantara14@gmail.com, \\ tamires.coelho.matias@gmail.com, claudia.marco@ufca.edu.br, agroflaviobatista@yahoo.com.br \\ ${ }^{2}$ Universidade Federal de Viçosa, Viçosa, Minas Gerais, Brasil. E-mail: iarley.toshik@gmail.com
}

Recebido: 21/05/2017; Aceito: 18//08/2018.

\section{RESUMO}

O manjericão (Ocimum basilicum) é uma das plantas medicinais e aromáticas mais consumidas no mundo, sendo seu óleo essencial amplamente utilizado nas indústrias químicas, farmacêuticas e de flavorizantes. No entanto, muitos fatores podem influenciar no teor do óleo essencial, dentre eles o horário de colheita das plantas. Com vista nisso, o objetivo deste trabalho foi avaliar o teor e fitoquímica do óleo essencial em cultivares de manjericão submetidos a diferentes horários de colheita. O experimento foi conduzido no Centro de Ciências Agrárias e da Biodiversidade da Universidade Federal do Cariri, Crato, Ceará. O delineamento experimental utilizado foi em blocos casualizados em esquema fatorial $2 \times 4$, com três repetições. Os fatores foram dois cultivares (Toscano Folha de Alface e Alfavaca Basilicão) e quatro horários de coleta (7, 10, 13 e 16 horas). A análise fitoquímica foi realizada na Universidade Regional do Cariri. O maior teor de óleo essencial foi obtido às 14 e 21 horas para os cultivares Alfavaca Basilicão e Toscano Folha de Alface, respectivamente. Quanto à análise fitoquímica, os cultivares apresentaram flavonoides, taninos e no cultivar Alfavaca Basilicão há, também, alcaloides.

Palavras-chave: Ocimum basilicum, cv. Alfavaca Basilicão, cv. Toscano Folha de Alface, fatores abióticos, bioprospecção.

\section{Content and phytochemistry of the essential oil of basil in different harvest hours}

\section{ABSTRACT}

Basil (Ocimum basilicum) is one of the most consumed medicinal and aromatic plants in the world, being its essential oil widely used in the chemical, pharmaceutical and flavoring industries. However, many factors can influence the essential oil yield, among them the harvest time of the plants. In view of this, the aim of this work was to evaluate the yield and phytochemistry of essential oil in basil cultivars submitted to different harvest time. The experiment was conducted at the Center of Agrarian Sciences and Biodiversity of the Federal University of Cariri, Crato, Ceará. The experimental design was a randomized complete block design in a $2 \times 4$ factorial scheme, with three replications. The factors were two cultivars (Toscano Folha de Alface and Alfavaca Basilicão) and four harvest times (7, 10, 13 and 16 hours). The phytochemical analysis was performed at the Regional University of Cariri. The highest essential oil content was obtained at 14 and 21 hours for Alfavaca Basilicão and Toscano Folha de Alface cultivars, respectively. As for the phytochemical analysis, the cultivars presented flavonoids, tannins and in the cultivar Alfavaca Basilicão there are, also, alkaloids.

Keywords: Ocimum basilicum, cv. Alfavaca Basilicão, cv. Toscano Folha de Alface, abiotics factors, bioprospecting. 


\section{Introdução}

O manjericão (Ocimum basilicum L. - Lamiaceae) é uma planta medicinal e aromática, podendo ser utilizada in natura e/ou processada. O seu óleo essencial, extraído principalmente das folhas e inflorescências, apresenta o linalol como componente majoritário (Favorito et al., 2011), sendo este utilizado como produtos farmacêuticos, cosméticos e flavorizantes.

Os óleos essenciais são metabólitos secundários e conferem o odor característico de cada planta, podendo ser extraídos de diversas partes destas. Seus constituintes químicos são principalmente os derivados dos compostos terpênicos, como os mono e sesquiterpenos e os fenilpropanoides (Miranda et al., 2016). Suas principais funções nos vegetais são: proteção contra viroses, bacterioses, infecções fúngicas e herbívoras, atuando, também, como atraentes ou repelentes de outros organismos e resistência a estresses ambientais (Taiz et al., 2017).

Muitos fatores podem influenciar na composição química, qualidade e teor dos óleos essenciais dos vegetais. Dentre eles, tomam destaque os fatores abióticos, como nutrição, pluviosidade, altitude, temperatura, época e horário de colheita, dentre outros (Paulus et al., 2016).

A composição química dos óleos essenciais é determinada por fatores genéticos, pelas interações planta/microrganismos, planta/insetos e planta/planta, idade e estádio de desenvolvimento, além da ação antrópica, e, também, por fatores abióticos: luminosidade, temperatura, pluviosidade, nutrição, época e horário de coleta. Quanto ao horário de coleta das plantas, torna-se de essencial relevância, sendo necessário definir o momento ideal para a coleta do material (Morais, 2009).

Observa-se que o aroma característico de cada planta torna-se mais acentuado de acordo com o horário do dia. Isso pode estar relacionado à concentração/liberação de óleo essencial naquele período, ou na proporção relativa de cada composto liberado. Assim, o horário de coleta das plantas torna-se um aspecto relevante na produção de óleos essenciais. Neste sentido, o objetivo deste trabalho foi avaliar o teor do óleo essencial e a análise fitoquímica de dois cultivares de manjericão (Ocimum basilicum L.) submetidos a diferentes horários de corte.

\section{Material e Métodos}

O experimento foi conduzido no Centro de Ciências Agrárias e Biodiversidade (CCAB) da Universidade Federal do Cariri (UFCA), na cidade de Crato, Ceará. Segundo a classificação de Köppen, o clima da região é caracterizado como Quente Semiárido Brando e Tropical Quente Subúmido, com temperatura média anual de 24 a $26^{\circ} \mathrm{C}$, precipitação pluviométrica anual de
1090,9 mm, com chuvas concentradas nos meses de janeiro a maio (FUNCEME, 2012).

$\mathrm{O}$ experimento foi desenvolvido em delineamento, em blocos casualizados em esquema fatorial $2 \times 4$, sendo dois cultivares (Alfavaca Basilicão e Toscano Folha de Alface) e quatro horários de corte das folhas (7, 10, 13 e 16 horas), com três repetições, totalizando 24 parcelas experimentais. Cada unidade experimental ocupou uma área de $7,2 \mathrm{~m}^{2}$ com três fileiras espaçadas a $0,30 \times 0,30 \mathrm{~m}$. O material vegetal utilizado para extração do óleo essencial foi folhas de manjericão (Ocimum basilicum) em seu pleno estado de desenvolvimento, colhidas aos 98 dias após semeadura (DAS).

As mudas de manjericão foram produzidas em bandejas de poliestireno (isopor) de 128 células, utilizando como substrato solo oriundo do local do experimento, esterco e vermiculita na proporção 1:1: $1 / 2$ (v/v). Assim como as demais olerícolas, o manjericão necessita de água e sol para ter desenvolvimento e produtividade. Desta forma, com auxílio de borrifador, as mudas receberam duas regas, uma no início da manhã e outra no fim da tarde, e após 21 DAS foram transplantadas para os canteiros. Foi utilizado o sistema de irrigação por microaspersão, com uma irrigação diária no período da manhã. Para cada tratamento foi avaliado o teor de óleo essencial (\%) das folhas e análise fitoquímica dos extratos das folhas de manjericão dos cultivares Alfavaca Basilicão e Toscano Folha de Alface.

A colheita manual das folhas para extração do óleo essencial foi realizada aos 77 dias após transplantio nos seguintes horários: 7, 10, 13 e 16 horas. Logo em seguida, foram levadas para o Laboratório de Tecnologia de Produtos (LTP) da UFCA, onde foram mensuradas suas massas e colocadas em balão de fundo redondo para extração do óleo essencial. Em cada horário de coleta das folhas foram registrados dados de temperatura $\left({ }^{\circ} \mathrm{C}\right)$ e umidade relativa (\%) através de termohigrômetro digital, conforme descrito na Figura 1.

A extração do óleo essencial foi realizada por hidrodestilação em aparelho tipo Clevenger no LTP/UFCA. Foram utilizadas $100 \mathrm{~g}$ de folhas frescas, as quais foram trituradas em pequenos pedaços, colocadas em balão de fundo redondo $(5 \mathrm{~L})$ imerso em 2,5 litros de água destilada, por um tempo de extração de 90 minutos, em temperatura próxima a $100^{\circ} \mathrm{C}$, seguindo metodologia descrita por Alencar et al. (1984).

A prospecção fitoquímica foi realizada no Laboratório de Pesquisa de Produtos Naturais (LPPN) da Universidade Regional do Cariri (URCA), Crato, Ceará. Foram utilizadas amostras frescas das folhas, coletadas manualmente horas antes de serem levadas ao LPPN-URCA para extração etanólica e, posteriormente, conduzindo para testes dos constituintes químicos (marcha química). 


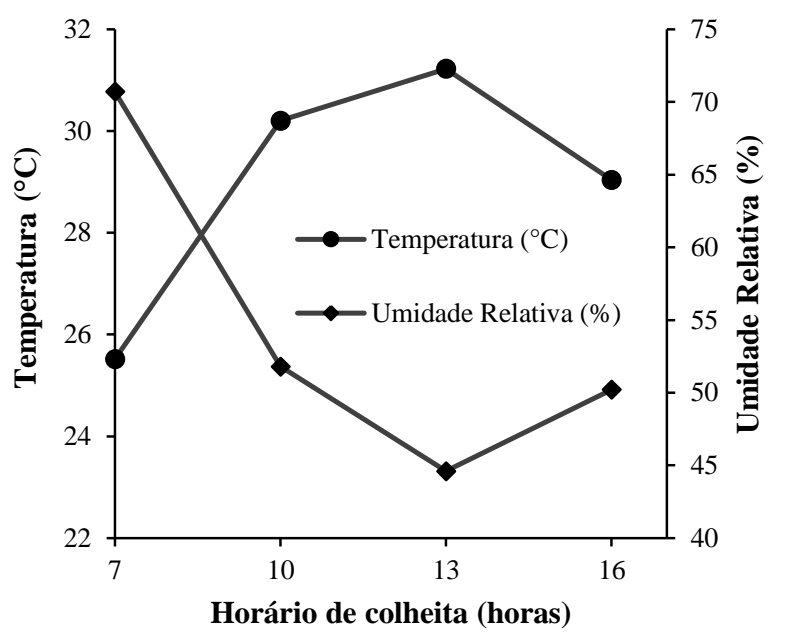

Figura 1. Dados climáticos do local do experimento no momento de colheita do material vegetal.

As folhas de manjericão foram separadas, mensuradas sua massa (100g) e adicionado $250 \mathrm{~mL}$ de álcool etílico P.A. (99,3\%), deixando assim o material vegetal totalmente submerso por $72 \mathrm{~h}$ sob temperatura ambiente. Em seguida, realizou-se a filtração e o material submetido à extração foi desprezado, enquanto o produto filtrado foi concentrado em rota-evaporador sob temperatura de $60^{\circ} \mathrm{C}$. Para que o solvente tivesse uma total evaporação, esse material foi colocado em recipientes de vidro e levado ao banho-maria numa temperatura de $100^{\circ} \mathrm{C}$ até a obtenção do extrato etanólico bruto.

A partir de cada material botânico extraído, foi preparada uma solução utilizando-se $0,3 \mathrm{~g}$ do extrato bruto das folhas, diluído em $100 \mathrm{~mL}$ de etanol (Matos, 1997). Foram separadas sete porções em sete tubos diferentes, contendo entre 3-4 $\mathrm{mL}$ dos extratos etanólicos das folhas em tubos de ensaio devidamente numerados e identificados para serem submetidos aos testes descritos a seguir.

\section{Teste para taninos e fenóis}

Foram adicionadas três gotas de solução alcoólica de $\mathrm{FeCl}_{3}$ e agitado por alguns segundos. Foi preparado, também, um teste "branco" com água destilada e cloreto férrico para comparações. A presença de fenóis ou taninos foi determinada de acordo com o aparecimento da coloração indicada para cada substância quando o teste "branco" for negativo. Coloração variável entre o azul e o vermelho é indicativa da presença de fenóis. Precipitado escuro com tonalidade azul, presença de taninos hidrolisáveis, coloração verde, taninos condensados.

\section{Teste para antocianinas, antocianidinas e flavonoides}

Foi feita a acidulação do tubo 2 a pH 3. Os tubos 3 e 4 foram alcalinizados a $\mathrm{pH} 8,5$ e 11 , respectivamente. A presença de antocianinas, antocianidinas e flavonoides foi identificada pelo aparecimento da coloração indicada para cada substância (Matos, 1997), como descrito na Tabela 1.

\section{Testes para leucoantocianidinas, catequinas e flavonas}

Foi feita a acidulação do tubo 5 com $\mathrm{HCl}$ até pH 1-3 e a alcalinização do tubo $6 \mathrm{com} \mathrm{NaOH}$ até pH 11. Logo em seguida, os respectivos tubos foram aquecidos com o auxílio de lâmpada de álcool por 2 a 3 minutos, ou até que se observasse ebulição (Matos, 1997). Foram observadas as possíveis alterações de cor e comparadas aos resultados do teste anterior de acordo com a Tabela 2.

\section{Teste para alcaloides}

Após a extração etanólica, mensurou-se $0,3 \mathrm{~g}$ do extrato obtido e diluiu-se em $30 \mathrm{~mL}$ de solução de ácido acético a 5\%. Logo em seguida, a mistura foi aquecida em banho-maria até sua fervura, por aproximadamente dois minutos, e transferida para um funil de separação, onde houve uma filtração parcial durante a transferência. A solução foi alcalinizada com hidróxido de amônio $\left(\mathrm{NH}_{4} \mathrm{OH}\right)$ a $10 \%$. Em seguida, foi adicionado $15 \mathrm{~mL}$ de clorofórmio submetido a uma agitação manual e deixou-se a solução em repouso por alguns minutos. Retirou-se do funil a fase clorofórmica ou alcaloídica, colocou-se em banho-maria sob temperatura de $60^{\circ} \mathrm{C}$ para evaporação do solvente, restando um resíduo que contém alcaloide. A esse resíduo adicionouse $\mathrm{HCl}$ a $1 \%$. Uma gota dessa solução foi colocada em vidro de relógio e, ao lado, uma gota de reagente de Draggendorff. Após mistura, as duas soluções ficaram em contato direto para que se observasse a sua reação. A presença de alcaloide pode ser observada quando o complexo obtido da reação gera um cromóforo de coloração, que vai do amarelo ao alaranjado. Contudo, a solução tende a adquirir coloração castanhoavermelhada devido à formação de iodo molecular.

Tabela 1. Indicação da presença de compostos nas amostras vegetais: antocianinas, antocianidinas, flavonas, flavonóis, xantonas, chalconas, auronas e flavononóis.

\begin{tabular}{lccc}
\hline Constituintes & \multicolumn{3}{c}{ Cor em meio } \\
\hline & Ácido & Alcalino ${ }^{(8,5)}$ & Alcalino $^{(11)}$ \\
\cline { 2 - 4 } Antocianinas e Antocionidinas & Vermelha & Lilás & Azul-púrpura \\
Flavonas, Flavonóis e Xantonas & - & - & Amarela \\
Chalconas e Auronas & Vermelha & - & Vermelho púrpuro \\
Flavonóis & - & - & Vermelho laranja \\
\hline
\end{tabular}


Tabela 2. Indicativo da presença de compostos de leucoantocinidinas, catequinas e flavonas nas amostras vegetais.

\begin{tabular}{lcc}
\hline Constituintes & \multicolumn{2}{c}{ Cor em meio } \\
\hline & Ácido & Alcalino $^{(11)}$ \\
\cline { 2 - 3 } Leucoantocianidinas & Vermelha & - \\
Catequinas (Taninos catéquicos) & Pardo amarelada & - \\
Flavonas & - & Vermelho laranja \\
\hline
\end{tabular}

Para a análise do teor de óleo essencial, os dados foram submetidos à análise de variância pelo teste $\mathrm{F}$ e, quando significativos, foram submetidos à análise de regressão utilizando-se o programa estatístico SISVAR 5.2 (Ferreira, 2011).

\section{Resultados e Discussão}

A influência do horário de colheita das folhas sobre o teor do óleo essencial de manjericão (Ocimum basilicum) é representada por uma curva de regressão polinomial quadrática (Figura 2).

A partir da derivação das equações, observou-se que o cultivar Alfavaca Basilicão apresentou seu maior teor de óleo essencial $(0,17 \%)$ às $14 \mathrm{~h}$, enquanto que o Toscano Folha de Alface apresenta seu maior teor $(0,27 \%)$ se for colhido às $21 \mathrm{~h}$. É de se ressaltar que se torna muitas vezes inconveniente a coleta desse último cultivar no horário em que o mesmo apresentou seu melhor teor, no entanto, em termos médios, o maior teor foi obtido às 13h. Quanto à primeira (Alfavaca Basilicão), o horário de maior eficiência apresenta-se como satisfatório para o manejo pós-colheita, visando a extração do seu óleo essencial. Resultados diferentes ao desta pesquisa foram encontrados por Carvalho Filho et al. (2006), onde o maior teor de óleo essencial de manjericão (Ocimum basilicum L.) foi obtido às 8 e 12 horas.

O maior teor para Alfavaca Basilicão coincide com a maior temperatura $\left(31,2^{\circ} \mathrm{C}\right)$ e menor umidade relativa do ar $(44,6 \%)$. Isso pode estar associado ao ajuste do metabolismo secundário da planta para lidar com o maior estresse nesse momento. Isso é de grande relevância, visto que as plantas passam por oscilações de temperatura durante o dia, tendo que se ajustar para que não haja dano ao seu metabolismo e, consequentemente, ao seu desenvolvimento. A umidade do ar também é de extrema importância, tendo-se que notar que, quando uma planta está sujeita a uma temperatura elevada e a umidade baixa, o déficit de pressão de vapor é alto, o que pode provocar o fechamento estomático e, consequentemente, a diminuição das trocas gasosas. Já no cultivar Toscano Folha de Alface, o maior rendimento durante o período noturno (quando a temperatura está amena e a umidade do ar mais elevada) pode ser consequência do armazenamento de metabólitos secundários (óleo essencial). O horário de colheita do material está relacionado tanto ao ambiente como à fisiologia da planta. É um fator importante, visto que para a extração de óleo essencial, esse aspecto pode interferir no teor e nos princípios ativos (Melo et al., 2011; Oliveira et al., 2012).

O óleo essencial do gênero Ocimum localiza-se em tricomas glandulares superficiais, sendo essas estruturas fragilizadas pelo ambiente, uma vez que são de fácil ruptura e de teor muito volátil. Alguns autores, estudando espécies da mesma família, também observaram resposta positiva em relação ao teor de óleo com o aumento na umidade e temperatura, observando que à medida que a temperatura e a umidade relativa se elevam, há um aumento no teor de óleo essencial (Deschamps et al., 2008; Botrel et al., 2010). Os resultados que se referem à classe dos metabólitos encontrados nos cultivares de manjericão através dos testes de prospecção fitoquímica podem ser vistos na Tabela 3. Os dois cultivares apresentaram as mesmas classes de compostos, com exceção do alcaloide, que foi observado, apenas, no cultivar Alfavaca Basilicão. A produção global de metabólitos nitrogenados por uma planta, por exemplo, alcaloides, geralmente é aumentada com a maior disponibilidade de nitrogênio no solo (Gobbo-Neto e Lopes, 2007), porém, neste experimento, os dois cultivares se desenvolveram no mesmo solo, o que não justificaria essa diferença encontrada.

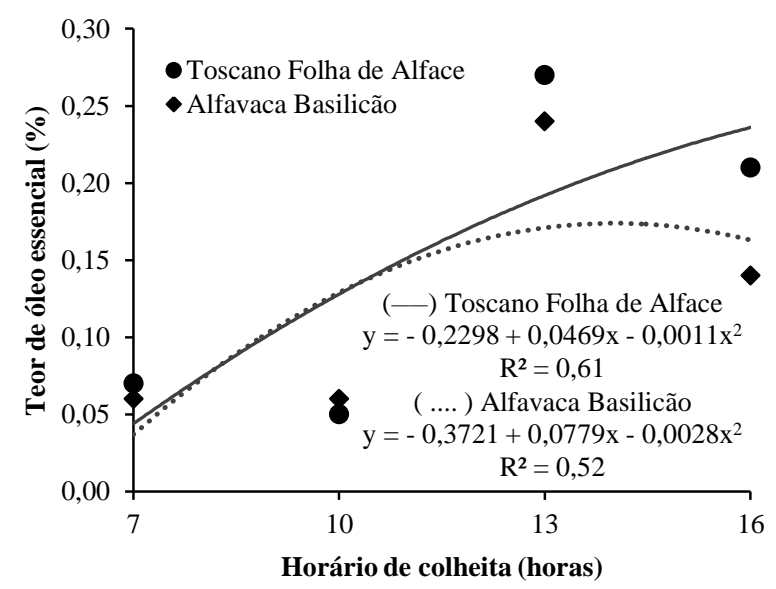

Figura 2. Teor de óleo essencial de Ocimum basilicum (cv. Toscano Folha de Alface e Alfavaca Basilicão) em diferentes horários de corte. 
Tabela 3. Prospecção fitoquímica das folhas de Ocimum basilicum

\begin{tabular}{ccc}
$\begin{array}{c}\text { Classe de metabólitos } \\
\text { secundários }\end{array}$ & $\begin{array}{c}\text { Alfavaca } \\
\text { Basilicão }\end{array}$ & $\begin{array}{c}\text { Toscano folha } \\
\text { de alface }\end{array}$ \\
\hline Taninos condensados & + & + \\
Flavonas & + & + \\
Flavonóis & + & + \\
Xantonas & + & + \\
Catequinas & + & + \\
Leucoantocianidinas & + & + \\
Flavononóis & + & + \\
Alcaloides & + & -
\end{tabular}

O sinal (+) indica presença e (-) ausência do constituinte químico.

Os alcaloides são compostos orgânicos cíclicos que possuem pelo menos um átomo de nitrogênio no seu anel, sendo produzidos pelo metabolismo secundário. São largamente utilizados como venenos e alucinógenos por possuírem relevante efeito no sistema nervoso (Vizzotto et al., 2010). Esses compostos são estruturalmente diversificados e apresentam um amplo uso na farmacopeia, destacando sua atividade anestésica, antitumoral, miorrelaxante e antimicrobiológica (Barbosa Filho et al., 2006).

As plantas sintetizam grande variedade de compostos fenólicos, os quais estão vinculados com funções primárias (fotossíntese, crescimento e desenvolvimento) e secundárias (atração de polinizadores e defesa). Plantas pertencentes à família Lamiaceae, como o manjericão, apresentam abundância em metabólitos secundários conhecidos como ácidos fenólicos. Esta espécie é rica em ácidos rosmarínicos, cafáricos e chicóricos (Mccance et al., 2016).

Esses compostos supracitados e outros compostos aromáticos conferem a esta espécie uma fonte de atividades antioxidantes, antimicróbicas e antitumorais (Tanase et al., 2018). Os compostos fenólicos ainda podem apresentar atividades anti-HIV, controle de diabetes e de doenças cardiovasculares (Teixeira et al., 2017). Com isso, a busca por espécies ou mesmo o aumento de seus teores em espécies já estudadas é de grande relevância para os estudos fitoquímicos e agronômicos. Flanigan e Niemeyer (2014) destacam que variações no teor de antocianinas de manjericão roxo podem ocorrer devido aos diferentes períodos de colheita das plantas, e que os níveis desse composto variam significativamente durante o crescimento e desenvolvimento das mesmas.

Com isso, evidencia-se que o teor de óleo essencial possui variação quanto aos horários de colheita para os cultivares avaliados e que os metabólitos secundários também podem ser distintos.

\section{Conclusões}

O maior teor de óleo essencial foi obtido às 14 e 21 horas para os cultivares Alfavaca Basilicão e Toscano Folha de Alface, respectivamente.

Os cultivares apresentaram flavonoides, taninos e no cultivar Alfavaca Basilicão há, também, alcaloides.

\section{Referências Bibliográficas}

Alencar, J.W., Craveiro, A.A., Matos, F. J. A., 1984. Kovats indices as a preselection routine in mass spectra library search of volatiles. Journal of Natural Products, 47(5), 890-892.

Barbosa Filho, J.M., Medeiros, K.C.P., Diniz, M.F.F.M., Batista, L.M., Athayde-Filho, P.F., Silva, M.S.; Cunha, E.V.L., Almeida, J.R G.S., Quintans-Júnior, L.J., 2006. Natural products inhibitors of the enzyme acetyl cholinesterase. Revista Brasileira de Farmacognosia, 16(2), 258-285.

Botrel, P.P., Pinto, J.E.B.P., Ferraz, V., Bertolucci, S.K.V., Figueiredo, F.C., 2010. Teor e composição do óleo essência de Hyptis marrubioides Epl., Lamiaceae em função da sazonalidade. Acta Scientarum. Agronomy, 32(3), 533-538.

Carvalho Filho, J.L.S., Blank, A.F., Alves, P.B., Ehlert, P.A.D., Melo, A.S., Cavalcanti, S.C.H., Arrigoni-Blank, M.F., Silva-Mann, R., 2006. Influence of the harvesting time, temperature and drying period on basil (Ocimum basilicum L.) essencial oil. Revista Brasileira de Farmacognosia, 16, 24-30.

Deschamps, C., Zanatta, J.L., Bizzo, H.R., Oliveira, M.C., Roswalkas, L.C., 2008. Avaliação sazonal do rendimento de óleo essencial em espécies de menta. Ciência e Agrotecnologia, 32(3), 725-730.

Favorito, P.A., Echer, M.M., Offemann, L.C., Schlindwein, M.D., Colombare, L.F., Schineider, R.P., Hachmann, T.L., 2011. Características produtivas do manjericão (Ocimum basilicum $\mathrm{L}$.) em função do espaçamento entre plantas e entre linhas. Revista Brasileira de Plantas Medicinais, 13, 582-586.

Ferreira, D.F., 2011. Sisvar: a computer statistical analysis system. Ciência e Agrotecnologia, 35(6), 1039-42.

Flanigan, P.M., Niemeyer, E.D., 2014. Effect of cultivar on phenolic levels, anthocyanin composition, and antioxidant properties in purple basil (Ocimum basilicum L.). Food chemistry, 164, 518-526.

FUNCEME, 2012. Levantamento de reconhecimento de média intensidade dos solos - Mesorregião do Sul Cearense. Fortaleza-CE: Fundação Cearense de Meteorologia e Recursos Hídricos.

Gobbo-Neto, L., Lopes, N.P., 2007. Plantas medicinais: fatores de influência no conteúdo de metabólitos secundários. Química Nova, 30(2), 374-381.

Matos, F.J.A., 1997. Introdução à fitoquímica experimental. Edições UFC, Fortaleza.

Mccance, K.R., Flanigan, P.M., Quick, M.M., Niemeyer, E.D., 2016. Influence of plant maturity on anthocyanin 
concentrations, phenolic composition, and antioxidant properties of 3 purple basil (Ocimum basilicum L.) cultivars. Journal of Food Composition and Analysis, 53, 3039.

Melo, M.T.P.D., Ribeiro, J.M., Meira, M.R., Figueiredo, L.S.D., Martins, E.R., 2011. Essential oil content of pepperrosmarin as a function of harvest time. Ciência Rural, 41(7), 1166-1169.

Miranda, C.A.S.F., Cardoso, M.G., Batista, L.R., Rodrigues, L.M.A., Figueiredo, A.C.S., 2016. Óleos essenciais de folhas de diversas espécies: propriedades antioxidantes e antibacterianas no crescimento espécies patogênicas. Revista Ciência Agronômica, 47, 213-220.

Morais, L.A.S., 2009. Influência dos fatores abióticos na composição química dos óleos essenciais. Horticultura brasileira, 27(2), S4050-S4063.

Oliveira, A.R.M.F., Jezler, C.N., Oliveira, R.A., Mielke, M.S., Costa, L.C.B., 2012. Determinação do tempo de hidrodestilação e do horário de colheita no óleo essencial de menta. Horticultura Brasileira, 30, 155-159.
Paulus, D., Valmorbida, R., Ferreira, S.B., Zorzzi, I.C., Nava, G.A., 2016. Biomassa e composição do óleo essencial de manjericão cultivado sob malhas fotoconversoras e colhido em diferentes épocas. Horticultura Brasileira, 34, 46-53.

Taiz, L., Zeiger, E., Møller, I.M., Murphy, A., 2017. Fisiologia e Desenvolvimento Vegetal. 6. ed. Artmed, Porto Alegre.

Tanase, C., Talmaciu, A.I., Bâra, I.C., Boz, I., Volf, I., Oroian, S., Popa, V.I., 2018. New aspects of biomass waste valorization: spruce bark crude extracts as plant growth regulators. BioResources, 13(2), 3994-4007.

Teixeira, T.S., Vale, R.C., Almeida, R.R., Ferreira, T.P.S., Guimarães, L.G.L., 2017. Antioxidant potential and its correlation with the contents of phenolic compounds and flavonoids of methanolic extracts from different medicinal plants. Revista Virtual de Química, 9(4), 1546-1559.

Vizzotto, M., Krolow, A.C.R., Weber, G.E.B., 2010. Metabólitos secundários encontrados em plantas e sua importância. Embrapa Clima Temperado-Documentos (INFOTECA-E). 